\title{
The last-mile logistical challenges of an omnichannel grocery retailer: A South African perspective
}

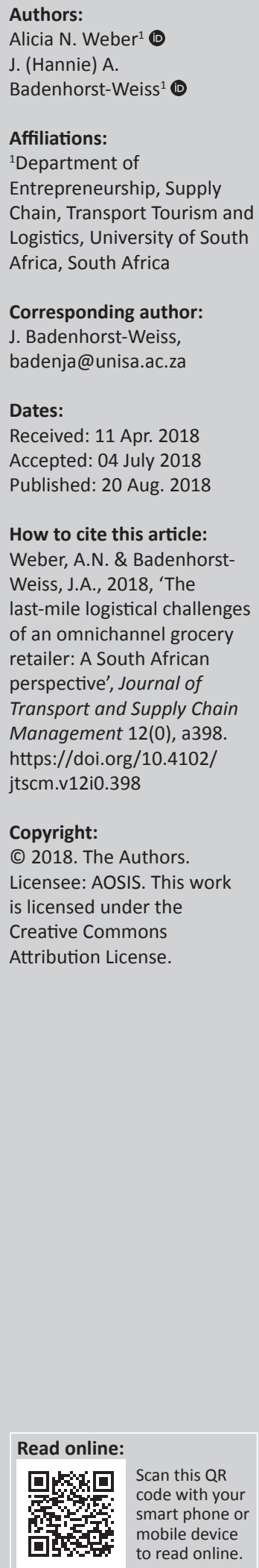

Background: The intense competition between grocery retailers to access new revenue streams has seen brick-and-mortar retailers broadening their services to offer consumers the option of ordering their groceries over the Internet. This is implemented through the implementation of different platforms such as their computer or mobile application - known as omnichannel retailing. Omnichannel grocery retailers are facing several challenges with the last mile of their online supply chain, especially with relation to the home delivery of groceries.

Objectives: The purpose of the article was to gain an understanding of the nature of last-mile logistical challenges hindering the efficiency of an omnichannel grocery retailer in South Africa.

Method: A qualitative methodology was employed; data were collected through an interview with the e-commerce operation manager of a well-known omnichannel grocery retailer in South Africa as well as through two focus group discussions conducted with consumers who regularly purchase items online and those who have never purchased any item online. Data were analysed using thematic analysis.

Results: The findings suggested that there are four major last-mile logistical challenges facing the South African omnichannel grocery retailer considered in this study. The challenges are reliable order fulfilment, cold distribution chain requirements, physical distribution and reverse logistics.

Conclusion: The findings of this article suggest that many of the last-mile challenges experienced by the omnichannel grocery retailer stem from the inefficient management of information (data) along the supply chain. To alleviate the last-mile logistical challenges identified in this article, emphasis should be placed on implementing a fully integrated information sharing system.

\section{Introduction}

\section{Background}

Growing interest by consumers to click their way through all aspects of daily life has fuelled the Internet economy to develop services and sell products online to meet specific consumer needs. The Internet provides organisations with the option to expand their service offerings by enhancing not only their business-to-business operations but also their business-to-consumer services (Mangiaracina et al. 2015:565). As the lines between online and physical channels are becoming increasingly distorted, a new approach to channel integration is evolving, namely omnichannel retailing (Piotrowicz \& Cuthbertson 2014:6). Omnichannels can be defined as: 'the synergetic integration of customer touch points and communication opportunities to create a unified brand experience regardless of channel, platform or stage in the selling process' (Cummins, Peltier \& Dixon 2016:5). Omnichannel retailing has emerged from multichannel retailing, which implied a detachment between the traditional brick-and-mortar store and the online store (initially through the website) (Hübner, Kuhn \& Wollenburg 2016:229). In omnichannel retailing, customers can move relatively freely between the online store (the website), the brick-and-mortar store and a mobile device (Bernon, Cullen \& Gorst 2016:586), while conveniently dictating when and how they prefer to receive their desired merchandise. In order to stay competitive and meet the demand set by consumers, retailers started to invest in countless last-mile delivery solutions, such as home-delivery, buy-online-pickup-in-store, lockers and free delivery upon minimum purchase levels (Lim, Jin \& Srai 2018:308).

Lim et al. (2018:309) report that the term 'last mile' was coined by the telecommunications industry and referred to the final leg of a network. Today, last mile signifies the last segment of 
a delivery process, which is often regarded as the most expensive, least efficient aspect of a supply chain and with the most pressing environmental concerns (Gevaers, Van de Voorde and Vanelslander (2014:399). Lim et al. (2018:309) critique the definitions of last-mile logistics presented by previous authors, arguing that previous definitions are incomplete and unable to capture the additional complexities driven by e-commerce in last-mile logistics, particularly in the omission of the origin of inventory. Therefore, Lim et al. (2018:310) define last-mile logistics as: ' ...the last stretch of a business-to-consumer (B2C) parcel delivery service. It takes place from the order penetration point to the final consignee's preferred destination point'. The definition of Lim et al. (2018:310) aims to address the gap in previous definitions of last-mile logistics through the addition of 'the order penetration point', which refers to an inventory location (e.g. fulfilment centre, manufacturer site, or retail store) and 'the final consignee's preferred destination point' indicating where an order will be delivered, commonly dictated by the consumer. Hence, with omnichannel retailing, retailers need not only align their service but also their operations, and specifically their last-mile logistic service as a well-designed omnichannel would see customers smoothly migrating between channels while providing a unified customer experience. The aim of an omnichannel is for consumers not to perceive the interaction with the channel, but rather with the brand - this challenges omnichannel retailers to manage all channels consistently (Piotrowicz \& Cuthbertson 2014:6). The Consumer Goods Forum (CGF) (2015:2) argues that omnichannels are rapidly becoming the engine of growth in the consumer goods and retail industry; however, only a few retailers are confident in their ability to execute a successful omnichannel strategy. Cascone et al. (2015:7) conclude that omnichannel retailing is no longer 'something to be considered' but instead has become a must-have for any industry to survive and thrive. As a result, even the most traditional retailers such as grocery retailers are transforming into omnichannel retailers.

In omnichannel retailing, integration is essential and refers primarily to data integration (Mirsch, Lehrer \& Jung 2016:4). Compared with the multichannel approaches, more data are fuelling the databases in omnichannel retailing. This has created new opportunities for data sources such as social and mobile channels to be utilised as a tool to gain insights into transactions and interactions with consumers. Consequently, a fully integrated omnichannel would see vast amounts of data gathered and analysed to create customer insights to correctly personalise consumer experiences (Cummins et al. 2016:6). Although these data insights could assist omnichannel retailers with strategic decision making, Kumar (2008:206) suggests that the unique characteristics of grocery products such as the perishability of food items coupled with home delivery have challenged even the most experienced logistic and supply chain managers. Hence, for omnichannel grocery retailers to be genuinely successful, they have to critically evaluate the unique logistical requirements of online grocery retailing, as these requirements will shape the trends of logistics in the last mile of the grocery supply chain.

\section{The gap in research and purpose}

Verhoef, Kannan and Inman (2015:174) identified with their study in multichannel retailing a research gap in omnichannel retailing and its surrounding challenges. Hübner et al. (2016:580) did a study on last-mile logistics in omnichannel retailing in the European Union and found that the most suitable fulfilment and delivery options for omnichannel retailers differ quite significantly between countries. These authors stressed that future research should be country specific, to ensure the results are generalisable to the specific country. Considering the above discussion, this article was cordoned off to deliberate on last-mile logistical challenges for the online part of an omnichannel grocery retailing firm in South Africa. The purpose of the article was to gain an understanding of the nature of last-mile logistical challenges hindering the efficiency of an omnichannel retailer in South Africa.

\section{South Africa and its readiness for omnichannel retailing}

South Africa is classified as a developing country with many inequalities. On the one hand, the country has a world-class sophisticated banking system, large successful national and multinational businesses, decent access to the Internet, excellent infrastructure and a growing middle-class living in metropoles. On the other hand, the country has a large poor (often unemployed - 26.7\%) (BusinessTech 2018) population living in underdeveloped rural areas with little access to resources, the Internet and infrastructure. The World Economic Forum's (WEF) 2016-2017 Global Competitiveness Report indicated that developing countries, such as South Africa, are not yet ready and equipped for this large-scale, advanced type of grocery retailing. This is supported by the findings of a study by Van Zyl (2015), which reports that of the 55.6 million South African citizens (Statistics South Africa 2016) only 25 million have bank accounts, of which only 14 million have access to the Internet; yet, just 2.3 million South African citizens use Internet banking services. These services play a crucial role in omnichannel retailing as the service requires a certain level of technological intricacy from its consumers. As a result, there is a relatively small market for South African omnichannel retailers to compete in, compared to the omnichannel market in developed countries. Nevertheless, Internet retail sales continue to be the most dynamic channel in the South African retail market (Euromonitor International 2015), and for South African grocery retailers to keep up with the advancements in this market, they will have to navigate and capture this relatively small market.

\section{Background of the omnichannel retailing firm that participated in the study}

The retailer participating in this study is one of the largest retailers in South Africa, selling clothing, footwear, accessories, groceries, beauty products and homeware. In the participating retailer's 2014 Annual Report, it listed eight long-term strategic objectives, one of which is to be the southern hemisphere's omnichannel leader: 
We are creating a relevant, personalised total retail experience for customers across all retail channels. This is enabled by innovative digital solutions and superior design to enhance the channelspecific experience. This will deepen our customer relationships, grow loyalty and drive sales growth. It is supported with physical store locations in a number of different formats - from convenience and department stores to supermarkets. (n.p.)

In the retailer's 2017 Annual Report it listed the expansion of their omnichannel strategy as a key objective for 2018 onwards ${ }^{1}$. During an interview with the online manager of the participating retailer, he confirmed that top management has recognised the value and opportunities of this form of retailing and is working towards capturing this valuable consumer market. As stated by the manager:

\begin{abstract}
'The multi-device customer of our world is a far more valuable real estate, and the reason is simple: we can see them. We can see the sessions crossing boundaries. We can see a session start from a desktop machine in the evening and migrates onto a tablet in the morning, migrates onto an office desktop during the day where he goes back onto a tablet in the evening checks, out on a smartphone later on. So it is the same shop, it is the same person, all they do is they swapping [sic] platforms and devices, and it is critical for us that we more geared [sic] towards that customer because that is a genuine transaction in progress'. Far more valuable to us than a once off [purchase].' (Personal interview, E-Commerce operations manager, Head Office of omnichannel retailer)
\end{abstract}

From the above discussion, it could be derived that business environmental factors in South Africa are conducive for omnichannel retailing and that some retailers in South Africa have realised the value of this opportunity. However, for these retailers, particularly grocery retailers, to tap into the omnichannel market, they will have to mitigate the challenges that accompany this type of retailing.

\section{Methodology and purpose Research design}

A descriptive qualitative research design was used for this study. This research design is particularly suited to provide a rich and detailed description of the experiences of multiple participants of a specific phenomenon or their views, opinions or perspective on a specific topic (Neergaard et al. 2009:2) with the purpose of exploring different perspectives of participants on a topic through the identification of underlying themes (Plano Clark \& Creswell 2015:289). A descriptive qualitative research design was deemed appropriate as the aim of this study was to gain an understanding of the nature of last-mile logistical challenges hindering the efficiency of an omnichannel retailer in South Africa. The data for this study were collected using two focus group discussions and one semi-structured interview.

\section{Focus group discussions}

For a descriptive qualitative research design, Neergaard et al. (2009:3) argues that focus group discussions are particularly 1.Name of company protected with a confidentiality agreement. pertinent to get a broad insight into the phenomenon under investigation. Cooper and Schindler (2014:133) state that focus group discussions are the simultaneous involvement of a small number of research participants (usually 6-10) who interact at the direction of a moderator, to generate data on a particular issue or topic. Two consumer focus group discussions were conducted at a guest house in Gauteng, one with consumers who have never purchased any item online (group one), and the other with a group of regular online shoppers (group two). Focus group participants were selected using non-probability or convenience sampling and more specifically judgemental and multiplicity (snowball) sampling. Both focus groups consisted of eight participants each, with male and female participants aged between 18 and 65, with different levels of education and with different cultural backgrounds. The duration of the focus groups were 75 min (group one) and 55 min (group two), respectively. The proceedings were led by a qualitative research consultant, while the researchers observed. The proceedings were audio recorded and transcribed by an independent transcriber.

\section{Interviews}

In South Africa, only two of the four major grocery retailers have an omnichannel strategy. Because grocery retailers in South Africa are operating in a highly competitive market (Meyer et al. 2017:2), one of the two retailers repeatedly declined an interview with the researchers. Nevertheless, one pilot interview and one in-depth interview were conducted with the e-commerce operations manager at the head office of one of the most well-known grocery retailers in South Africa (refer to the background above), a position he held for the past 16 years. Turner (2010:757) states that pilot interviews form an important part of interview planning as the pilot interview will assist researchers in determining if there are flaws, limitations or other weaknesses within the interview design and will allow the researcher to make the necessary revisions. In addition to the pilot interview, one semistructured in-depth interview with open-ended questions was conducted with the e-commerce operations manager of the participating grocery retailer. The duration of the indepth interview was $73 \mathrm{~min}$ in total.

This article forms part of a larger qualitative study which aimed to identify all barriers and motivators of omnichannel grocery retailing for both retailers and consumers in South Africa. The more extensive study is henceforth referred to as phase 1 of the data analysis of this article. Data for phase 1 were collected using a website analysis of both omnichannel retailer's websites, two consumer focus groups and two indepth interviews. The data corpuses collected during phase 1 were analysed using thematic analysis and several themes, categories and codes related to barriers and motivators of online grocery retailing were identified. One of the themes which emerged from phase 1 was last-mile logistical challenges. Four categories related to the theme 'last-mile logistical challenges' emerged from phase 1 of the data analyses: reliable order fulfilment, cold distribution chain requirements, physical distribution and reverse logistics. 


\section{Purpose}

The purpose of this article is to gain an understanding of the nature of last-mile logistical challenges hindering the efficiency of an omnichannel grocery retailer in South Africa, which was identified in phase 1 of the data collection. Essentially, when determining the 'nature of' something, it entails a significant comprehension of the fundamental character or characteristics of that unit of analysis, which makes qualitative research the most favourable methodology. To achieve the purpose of this article, a primary and two secondary research questions (SRQs) guided the researchers. The primary research question (PRQ) was:

- PRQ: Which last-mile logistical challenges are experienced by omnichannel retailers in South Africa?

The SRQs aim to determine how these last-mile logistical challenges influence omnichannel grocery retailers and how they manage these challenges. Questions were as follows:

- SRQ1: How do the last-mile logistical challenges influence the omnichannel retailer in the South African market?

- SRQ2: What measures could be employed to reduce the impact of these last-mile logistical challenges on the omnichannel retailer in South Africa?

\section{Data analysis}

The analysis of the in-depth interviews with the online manager and the two consumer focus group discussions were conducted in two phases. During phase 1, the transcribed datasets for the larger study were analysed and 'last-mile logistical challenges' was identified as one of the most prominent barriers the retailer face with online grocery retailing in South Africa. The theme 'last-mile logistical challenges' comprised four codes, that is, reliable order fulfilment, cold distribution chain requirements, physical distribution and reverse logistics. However, after analysing the data corpus for the more extensive study, it became apparent that further analysis into these four codes would provide a deeper understanding of the nature of these four challenges' influence in the last mile of the supply chain. Subsequently, the researchers embarked on phase 2 of the analysis. Here, the researchers specifically coded the data with the aim of unravelling the underpinning challenges related to the four codes identified in phase 1 .

\section{Thematic analysis}

Thematic analysis was used to analyse the qualitative data for this study (in both phases 1 and 2). Braun and Clarke (2013) argue that many researchers confuse thematic data analysis with the more commonly known qualitative data analysis method - content analysis. Thematic analysis differs from content analysis, as the themes identified through thematic analysis are not quantified - the value of the analysis is housed in the words of the participants. Thus, thematic analysis provides the researcher with a 'thicker' representation of the data. Thematic analysis is defined by Smith and Firth (2011) as:
... an interpretive process, whereby data are systematically searched to identify patterns within the data to provide an illuminating description of the phenomenon. The process results in the development of meaningful themes without explicitly generating theory. Thematic analysis can provide rich and insightful understandings of complex phenomena ... (p. 57)

The process of thematic data analysis consists of six sequential steps. The steps are familiarisation with the data, generating initial codes, searching for themes, reviewing themes, defining and naming themes and producing the report (Vaismoradi, Turunen \& Bonda 2013:402). These steps were meticulously followed for each of the three datasets (transcribed interviews and two focus group discussions) individually; thereafter, the data corpus was combined to identify differences and similarities between the categories, themes and codes.

\section{Trustworthiness}

Frequently, qualitative research is evaluated against criteria suitable to quantitative research in terms of reliability and validity and is found to be deficient. Qualitative researchers argue that, because of the difference in nature and purpose of quantitative and qualitative research, it is flawed to apply the same criteria for trustworthiness or merit (Weber \& Badenhorst-Weiss 2016). Trustworthiness in qualitative research is normally associated with credibility, dependability, transferability and confirmability (Eriksson \& Kovalainen 2008:307) and is usually established through the application of multiple data collection methods to enhance the level of rigour in qualitative research. According to Shenton (2004:64), credibility in qualitative data refers to the internal validity of the data. On the other hand, dependability means that should the research be replicated, similar results would be achieved. In this study, both credibility and dependability were established through the use of triangulation. Triangulation refers to 'overlapping methods', that is, the collection of data from different sources (and methods) in order to obtain more wide-ranging or holistic findings (Shenton 2004:71). As discussed above, data for phase 1 were collected by means of website analysis, two focus group discussions and an indepth interview. Transferability refers to external validity, meaning the degree to which the findings of a study can be generalised to any other situations (Saldaña 2011:112). Transferability can be achieved by providing a thick description of the research design through accurate databases and representation of the data collection methods and analysis. Transferability was achieved through the audio recording and transcription of both the interview and focus group data. During phase 2 of the data analysis, the dataset from phase 1 was re-coded and re-analysed specifically through the lens of challenges related to last-mile logistics. Confirmability refers to the objectivity of the research most commonly determined through the audit trail kept by the researcher. According to Carcary (2009:16), research audit trails may be physical (documents) or intellectual (the researchers thinking process) in nature. For the purpose of this study, the physical audit trail was kept by means of raw 
data, transcriptions and thematic data analysis documents. The intellectual audit trail is established through the presentation of this article. To present this article in the most organised and logical manner, the discussion on the literature and empirical findings is interwoven and discussed as a whole (below) instead of fragmented between sections - an acceptable practice in qualitative studies (Creswell 2009:81).

\section{Literature review and qualitative findings}

Technology has empowered consumers in terms of access to more information and consequently more buying options which have occasioned consumers who seek consistent, seamless shopping experiences through all available channels or 'Omnichannels' (Cascone et al. 2015). Retailers benefit from omnichannel retailing as multiple channels allow retailers to market their products and increase sales by accessing customers across all segments and levels of technological sophistication. As a result, retailers can now provide a customised shopping experience for consumers who place their orders via their preferred channel(s) on a $24 \times 7$ basis. However, this mode of retailing has not come without challenges for both retailers and consumers. Consumers are concerned about security, product quality, uncertainty in terms of delivery and a loss of the social or entertainment function (Hsu, Huang \& Swanson 2010; O'Cass \& Carlson 2012), while retailers are facing their own challenges such as large expenditure, delivery or logistical challenges and supply chain risks (Reinartz et al. 2011). Hübner et al. (2016:572) found that 6 out of 10 challenges with omnichannel grocery retailing have their roots in last-mile fulfilment. One factor that adds to the difficulties is that the average online grocery shopping basket contains 60-100 items - up to 60 times more than non-food online orders. The findings of the WEF (20162017) and Punakivi and Saranen (2001) suggest that one of the most significant barriers impeding the growth of e-commerce is the lack of suitable home delivery infrastructures. The aforementioned barrier is problematic because the contact between the omnichannel retailer and the final consumer is an essential part of the end-to-end electronic supply chain. To put the specific identified logistical challenges into perspective, a diagram, as presented in Figure 1 was developed. Thus, Figure 1 serves as a simple visual representation of the generic process of omnichannel retailing.

From Figure 1, it is noticeable that the process starts with the need or intent of the consumer to purchase a product. The consumer then selects one of the available channels (brickand-mortar store, the website or the mobile platform). After that, the consumer either purchases (brick-and-mortar) or orders (website and mobile platform) the item he or she was looking for or leaves the respective omnichannel. However, if the customer orders the product via one of the online platforms (the website or mobile), the process becomes the responsibility of the omnichannel retailer to fulfil, package and deliver the order.
Considering Figure 1, it is noticeable that last-mile logistics requires several factors to be in synergy (e.g. stock availability, packaging, delivery) to complete the 'perfect order'. Traditionally, fast-moving consumer goods in brick-andmortar supply chains were built only to deliver goods to stores. Omnichannel retailing has changed this 'traditional' function of the supply chain, as omnichannel supply chains have become a consumer-facing front office and one of the key determinants of customer satisfaction. As a result, omnichannel retailers have to develop completely new logistical structures in which technologies, such as the Internet, are used to integrate all parties in the supply chain (Coyle et al. 2017). The 'traditional' supply chain needs to be re-engineered for this new type of retailing. Yrjölä (2001) is of the opinion that the logistical challenges retailers face could be traced back to the fact that brick-and-mortar retailers have built their online offering 'on top' of their traditional grocery shop, secondary to traditional brick-and-mortar retailing. This argument is supported by the findings of the CGF (2015) who surveyed 42 senior supply chain executives from the world's most significant consumer goods and retail companies. In their study, they found that $81 \%$ of senior supply chain managers believe that their supply chain is not fit for omnichannel retailing.

Gallino and Moreno (2014) argue that for retailers to reach their full potential in an omnichannel environment, internal integration becomes a crucial success factor which would see flexible order fulfilment processes with technology as an enabler. The CGF (2015) found that the sheer pace of change in omnichannels results in ill-considered and irrational behaviour from retailers. Consequently, to achieve success in omnichannel retailing, strategies must be designed according to the changing needs of consumers. Essentially, retailers need to determine where in the omnichannel process value is truly created for the consumer, for example, offering an accurate view of delivery times or specific time slots might add more value for the consumer concerning same-day or next-day delivery. Furthermore, omnichannel strategies need to be embedded in the end-to-end supply chain thinking (Zarella, Chamberlain \& Liddel 2016) from the strategic choices regarding the retailers' general business practices to product packaging and design.

This study focuses specifically on gaining an understanding of the nature of last-mile logistical challenges hindering the efficiency of omnichannel retailers. During the larger study, four last-mile logistical challenges were identified as barriers to the successful implementation of omnichannel retailing strategies. These four challenges were reliable fulfilment of online orders, cold distribution chain requirements, physical distribution challenges and reverse logistics. They will be discussed individually below.

\section{Last-mile logistical challenges}

Considering the nature of omnichannel retailing, Hübner et al. (2016:577) argue that an omnichannel strategy does 


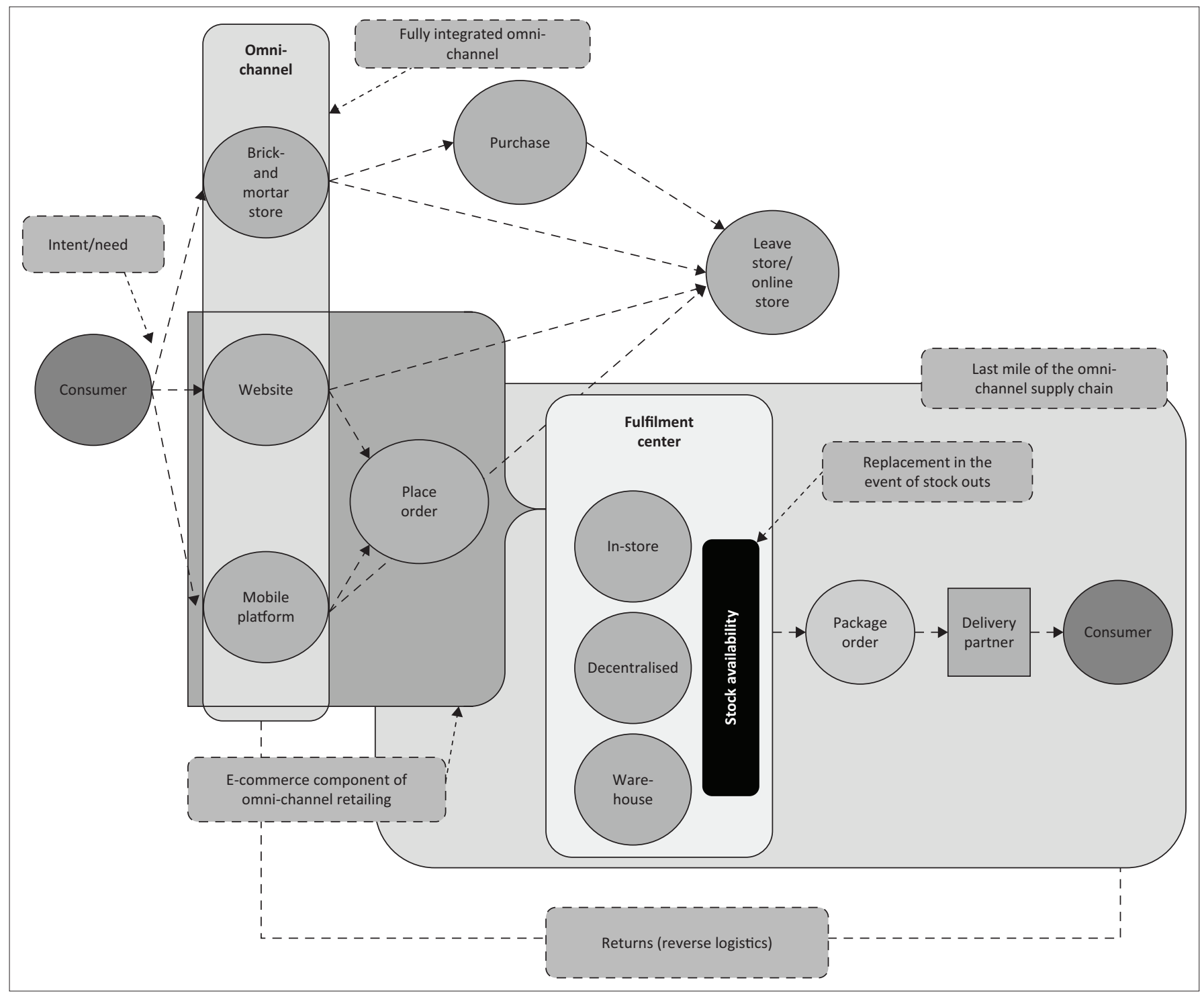

FIGURE 1: Generic process of omnichannel retailing.

not only provide for an online ordering service but also several associated services, such as logistics, customer service, network design and service response logistics. Delivery is the only physical touch point the retailer has with a consumer, and therefore it could be argued that the delivery could significantly impact the customer's perception of omnichannel retailing. As a result, efficient logistics management becomes crucial for retailers intending to adopt omnichannel retailing. For the purpose of this study, logistics management is defined as the part of supply chain management that plans, implements and controls the efficient forward and reverse flow and storage of goods, services and related information between the point of origin and the point of consumption to meet customers' requirements (Johnson, Leenders \& Flynn 2011; Monczka et al. 2016; Wisner, Tan \& Leong 2016).

The next section of this article will present an in-depth discussion of both the literature as well as the empirical findings of the four last-mile logistical challenges identified as part of phase 1 of the larger study.

\section{Reliable fulfilment of online orders}

Omnichannel retailing means more complex distribution systems for retailers, as some of the physical aspects of retailing which is the responsibility of the consumer in a conventional retail setting become the retailer's task with online retailing - for example, picking of fresh food products such as meats and fruits (Xing et al. 2011). Consumers in a traditional grocery shopping setting would be able to select alternative products to replace out-of-stock items (Kumar 2008). The gap between what consumers order and what they receive could result in consumer churn. The reasons being that customers who purchase their groceries online are demanding convenience while expecting reliable, on-time home delivery and exactly what they order (Al-Nawayseh et al. 2013). Many consumers complain that when the product they ordered is out of stock, the product replacement is not what they would have picked for themselves because of their loyalty to specific brands (Ailawadi \& Farris 2017; Kämäräinen 2001; Rafiq \& Fulford 2005). This refers to one of the first codes, identified as the last-mile logistical challenge, that is, incomplete or incorrect orders are problematic. 


\section{Incomplete or incorrect orders}

'Incomplete (or incorrect) orders' are a barrier for online consumers and retailers. Omnichannel retailers also consider order fulfilment and stock availability as a major logistical challenge. In a survey conducted by the CGF (2015), it was found that $51 \%$ of omnichannel retailers were unable to meet the demand spikes as a result of marketing initiatives. Furthermore, the research found that $40 \%$ of omnichannel retailers have no mechanism to fulfil out-of-stock goods until the channel receives its pre-ordered stock; stock-keeping errors exacerbate this situation.

During the interviews, the online manager also indicated that one of the most significant challenges for their firm is to fulfil the 'perfect' customer order. He indicated that many of the customers' dissatisfaction with the service was as a result of the so-called 'imperfect' orders:

'The reality is that our availability, at first pick, so before we do any substitution, is somewhere between eighty-eight and ninety-five percent, depending on the store. So eighty-eight to ninety-five. So let's take a best case example. You have a five percent margin for error already. Our reliability of on-time delivery I think is pretty good. Our target is ninety-eight, we are achieving about ninety-seven point five per cent. But let us say that is another three per cent ... that is a seven or eight percent difference between what you have promised and what you do. That's a huge margin, and in the customers' mind that's too big.' (Personal interview, E-commerce operations manager, Head Office of omnichannel retailer)

'It is different if you put that product into a dark warehouse where only online has visibility. You can be more sure [sic] that you have the products available, but the cost implications of doing it are enormous.' (Personal interview, E-commerce operations manager, Head Office of omnichannel retailer)

During the two focus group discussions, stock-outs (or not receiving a complete order) were mentioned by several of the participants as being the origin of their frustration.

'... later on I decided this is not working for me any longer. The reason for it is that out-of-stocks became a huge problem for me ...' (Participant 3, Focus group 2)

'You order it, and you pay it, and then they phone you, okay, it is out of stock, and then I have already paid so then it is a mission to get your money back ...' (Participant 4, Focus group 1)

Consequently, omnichannel retailers face the challenge of going to great lengths to ensure that they have the products in-stock before a consumer places an order online. This can only be achieved through efficient information sharing with supply chain partners (Sezen 2008). The CGF (2015) supports this view, indicating that standardisation and synchronisation of information availability among channels and partners become essential for omnichannel retailers as the loop between retailers and consumers need to be closed. Integrated order management and fulfilment systems allow the accessibility of up-to-date information on available inventory not only for omnichannel retailers but also suppliers, stores and online customers (Coyle et al. 2017). Efficient information sharing allows omnichannel retailers to be innovative when fulfilling online orders, for example, if only part of an online order is located at a specific store, that order can be pooled with the rest of the order from another store and shipped in one package to the customer, thus improving the customer experience (Ishfaq et al. 2016). In an attempt to address this challenge, the omnichannel retailer has emphasised improving the information flow along the omnichannel supply chain to reduce the margin of fulfilment error and to increase customer satisfaction with the service.

'We are continually refining our point of view of what we have available to try and make it as real-time as possible. We are running at the moment on fifteen-minute intervals. We are running data into the site every fifteen minutes to try and get as close to the truth of what we think we have available as possible [sic].' (Personal interview, E-commerce operations manager, Head Office of omnichannel retailer)

Although online order fulfilment at different locations decreases the possibility of stock-outs, it simultaneously increases order fulfilment costs (Mahar, Wright \& Bretthauer 2011). The CGF (2015) indicates that the decision regarding the fulfilment method is largely determined by a trade-off between efficiency (cost) and agility. The authors argue that in some cases cost will serve as the deciding factor (demanding efficiency) in terms of the cost of the fulfilment method while in other cases the speed of delivery will be considered more important (emphasising agility).

One of the most import decisions omnichannel retailers need to make is how to fulfil customer orders. In general, there are three standard models for the fulfilment of online orders. These include in-store order fulfilment, separate (decentralised) fulfilment centres and central warehouse. Table 1 briefly describes each of these options.

No fulfilment method is better than the other; however, because of the cost of adding additional distribution channels, most retailers start off by fulfilling online orders from their pre-existing retail stores (i.e. in-store), then expanding as demand grows into dark stores and beyond. Marchet et al. (2018:447) argue that when retailers decide on a fulfilment model, they should find a balance between likely demand, customer needs, existing footprint and available capital investment case. Even if the perfect order could be fulfilled, several other elements need to fall into place before a customer would receive the 'perfect' order. One of these elements is the arrival of the grocery products the customer

TABLE 1: Picking and/or fulfilment options for omnichannel retailers.

\begin{tabular}{ll}
\hline Picking option & Description \\
\hline In-store & $\begin{array}{l}\text { A professional order picker fulfils the online order by } \\
\text { collecting groceries directly from the shelves of the closest } \\
\text { brick-and-mortar store of the omnichannel retailer. }\end{array}$ \\
$\begin{array}{ll}\text { Separate (decentralised) } \\
\text { fulfilment centre or }\end{array}$ & $\begin{array}{l}\text { These fulfilment centres are dedicated solely to the } \\
\text { fulfilment of online orders and are usually strategically } \\
\text { located close to large consumer markets. }\end{array}$ \\
Central warehouse & $\begin{array}{l}\text { Large warehouses (usually heavily automated) fulfil } \\
\text { customer orders for direct distribution to the customers. }\end{array}$ \\
\hline
\end{tabular}

Source: Adapted from Hübner, A., Kuhn, H. \& Wollenburg, J., 2016, 'Last mile fulfilment and distribution in omnichannel grocery retailing. A strategic framework', International Journal of Retail and Distribution Management 44(3), 228-247. https://doi.org/10.1108/ IJRDM-11-2014-0154 
ordered on-time and in the same condition as the customer would expect when purchasing the product in-store. This presents omnichannel retailers with the next to last-mile logistical issue: cold distribution chain requirements.

\section{Cold distribution chain requirements}

It is well-known that temperature is an important parameter in food safety and quality (Kuo \& Chen 2010). Perishable foods are a fundamental source of income for grocery retailers and it is understandable why omnichannel retailers have gone to great lengths to, not only, ensure the correct temperature control of perishable food items during storage but also to ensure that online logistic partners are mindful of the cold-chain requirements for home delivery of food items. With this form of retailing, the omnichannel retailer takes the risk of exposing perishable foods to conditions which could potentially degrade the quality of the food. Therefore, it is imperative that supply chain managers strategically analyse cold-chain requirements of online retailing (Aiello, La Scalia \& Micale 2011).

Cold-chain requirements are especially tricky in online grocery retailing because the 'basket' of items delivered to a customer can be a large assortment of products with individual optimum temperatures such as frozen, refrigerated or dry. All these items must be delivered with the same vehicle on one temperature setting (Rong, Akkerman \& Grunow 2011). During the interview, the online manager stressed that because of the temperature-sensitive nature of some grocery products, they had been restricted regarding their expansion into other geographical areas for online grocery delivery. As stated:

'The challenge for us and the bit that is holding us back is how do you package that proposition logically for an online customer? You can have this, but you cannot have this. You can have clothing, but you cannot have food.' (Personal interview, E-commerce operations manager, Head Office of omnichannel retailer)

The requirements for a grocer's cold-chain are not merely delivering the food products freshly and safely at the right temperature, but include on-time delivery. The online manager indicated that the nature of grocery products further complicates this form of online retailing as the urgency (time expectations) with which consumers need the grocery items is higher than for any other products purchased online. It was noted:

'A lettuce is ... I order it today, I want it here, and I want it delivered, and there is no point in delivering it in two days' time. Deliver it when I need it. So unless you change your proposition, you cannot package the fact that you might fail ... you can limit the risk by cutting down the proposition, but for a foods online retailer, it is very hard to do. It is very hard to have hundred percent reliability in a food supply chain.' (Personal interview, E-commerce operations manager, Head Office of omnichannel retailer)

For consumers, perishable grocery products fall in the see or touch or feel category (Mortimer et al. 2016), meaning consumers prefer to purchase these items by physically evaluating their quality. If the quality of the perishable grocery item delivered to the customer is not on standard, the customer distrusts the entire omnichannel shopping process and not simply the one sub-standard order fulfilment. As stated participant 2:

'... perishable stuff, for example, tomatoes, they always pick the ripest tomatoes. Now everything is ripe and now you have to either make sauce or soup or something just to make use of it, and that was not necessarily the plan.' (Participant 2, Focus group 2)

General online retailers face several logistical challenges. However, considering the above, it becomes noticeable that omnichannel grocery retailers face the additional challenge of food being spoilt during the last mile of the distribution chain. It becomes clear that delivery time is a crucial logistical issue with perishable grocery items. This even influences the geographical market span of the omnichannel grocery retailer. Although 'cold-chain requirements' is inherently part of the physical distribution (next theme below), it was coded as a separate theme because of the extent to which it influences the last-mile logistics. The next theme, physical distribution challenges, will consider general challenges experienced in the omnichannel.

\section{Physical distribution challenges}

Physical distribution in the last mile of the online grocery supply chain can be laborious. Omnichannel retailers often face the challenge of using and managing third- and fourth-party logistics providers (Fairchild 2016). These service providers need to adhere to the specific time-slot indicated by the final consumer. Also, depending on the fulfilment model, consumers need to be at the delivery address at the particular time-slot to receive the grocery items. Therefore, many variables need to fall into place to ensure one successful delivery to satisfy one customer. From the consumer's perspective, the delivery component of omnichannel retailing is also laborious. Although several authors (Chopra 2016; Ishfaq et al. 2016) cite the convenience of omnichannel retailing as a motivator for consumers to purchase their groceries online, contrarily some focus group participants allude to feeling confined to a specific delivery date and time when buying their groceries online. Participants stated the following:

'I do not know if I am going be at the house between four and five for delivery, my circumstances are not like that ...' (Participant 3, Focus group 1)

'I have no idea from day to day where I am or what I am doing ... you feel restricted.' (Participant 2, Focus group 1)

Accordingly, physical distribution is one of the fundamental processes within omnichannel retailing, which should be managed efficiently to ensure customer satisfaction and omnichannel success. Fairchild (2016) reasons that omnichannel retailers should utilise the expertise of the thirdand fourth-party logistics providers to manage the physical distribution of products in the omnichannel efficiently. 
The core business of omnichannel retailers is having the correct selection of merchandise available for their customers. Consequently, most omnichannel retailers outsource the delivery of the grocery products to third parties. According to Chopra and Meindl (2016), the decision to outsource should be based on weighing up the growth in (supply chain) surplus gained by outsourcing, against the increased risk incurred by using a third-party distributor. Outsourcing holds the disadvantage of condensing profit margins and reducing control over customer information and satisfaction (Fairchild 2016). When considering the importance of the quality of a physical distribution service for online grocery retailers, inefficient outsourcing could hold massive reputational risks for omnichannel retailers. Consequently, omnichannel retailers should have high levels of trust in their outsourced suppliers for logistic services (Mahar et al. 2011). During the interview, the online manager referred to the extent they have to rely on their outsourced partners to be able to ensure a successful delivery service:

'We hope the delivery partner arrives on time. We hope he does not have an accident on the way to the customer. We hope he has enough capacity today to deliver all the customers' orders.' (Personal interview, E-commerce operations manager, Head Office of omnichannel retailer)

Nevertheless, the online manager suggested that they consider the use of third-party service providers as an advantage. Through the utilisation of the third-party's knowledge and experience in the field of logistics, the omnichannel retailers gain access to valuable resources in an area with which they are relatively unfamiliar with:

'We have huge distribution partners. They have the skills for doing this stuff ... so we try and leverage what they know about delivery ....' (Personal interview, E-commerce operations manager, Head Office of omnichannel retailer)

The service is further complicated as South African consumers are 'spoilt for choices'. Because of a lack of an extensive public transportation system and suburbanisation, extensive retail areas developed in the suburbs in South Africa, meaning South Africans have several closely located grocery stores to choose from, which decreases the need for online grocery retailing in specific areas. Thus, the advantage of density is lost, and orders are dispersed over wide geographic areas. This is seen in the verbatim quote below:

'... we have long inter-order drop distances, far. Our density is very, very low.' (Personal interview, E-commerce operations manager, Head Office of omnichannel retailer)

When asked to compare online grocery shopping in a developing country such as South Africa with a developed country such as the United Kingdom, the online manager said:

'They look at our delivery distances between orders, and can't believe it. They cannot believe we drive forty/fifty kilometres between drops. They are driving hundreds of metres at the most. So the densities are just staggeringly different ... those vehicles travel literally half a block before the next drop. We are covering halfway across Johannesburg to make two deliveries.' (Personal interview, E-commerce operations manager, Head Office of omnichannel retailer)
To minimise the effect of this logistical challenge, South African omnichannel retailers had to come up with innovative ways of saving costs and eliminating the duplication of tasks. One of these creative ways is the use of trucks which were exclusively utilised for online deliveries in other parts of the business, to save cost and optimise operations. These online delivery trucks are specifically used to replenish merchandise at small filling station shops of a national fuel company with whom a retailer has a strategic partnership. As stated below:

'We have the ability to leverage vehicle utilisation across the multiple tasks. So where we only need vehicles for online for a third of the day, we can't carry the total cost of that vehicle just in online. So what we might be able to do is leverage that vehicle for twenty-four hours and carry some of the costs for online and do some other work in the other part of the day ... [sic] We have got taxi-type tasks for those vehicles to do. Because we have quite a strong strategy around X [a national fuel company] and our X Foods group those little stores require a distribution that is quite similar to online. It tends to be small volumes, quite broad spread. [sic]' (Personal interview, E-commerce operations manager, Head Office of omnichannel retailer)

As seen from the quotations above, cost considerations are an essential part of planning for online distribution. Consequently, the cost of physical distribution was identified as a code forming part of the physical distribution challenge that omnichannel retailers face when offering groceries for purchasing online.

As mentioned earlier, several aspects which are the responsibility of the consumer in traditional retailing become the responsibility of the omnichannel retailer in online grocery retailing, for example, the cost of delivery. Although most online retailers charge consumers a delivery fee (Milkman, Rogers \& Bazerman 2010), in a traditional retail setting, the consumer would be responsible for ensuring the food they purchase arrives home. The delivery fee associated with online retailing asserts a central barrier for consumers to purchase most of their products through an online channel (Mortimer et al. 2016). Participants from the focus group discussions echoed this sentiment:

'... if you have to pay the delivery fee every single week, it adds up.' (Participant 5, Focus group 2)

'For me, it was to measure up whether the thirty to fifty rand delivery justifies me actually going to the store or not. Although it does not sound like much but within my reasoning, I thought you know, no.' (Participant 3, Focus group 1)

Even though the consumers pay a delivery fee, during the interviews, the online manager indicated that the delivery fee is not sufficient to cover the cost of offering the service. In an attempt to reduce the cost barrier for consumers, the participating omnichannel retailer has created an unsustainable delivery model which is costing them a fortune. See statement below:

'... we have held our cost of delivery for five years with no movement. So we have increased our subsidy every year for the last five years, and there it is a real worry for us ... So we have 
absorbed that cost every year for five years, ... it is not sustainable, the way that it is. [sic]' (Personal interview, E-commerce operations manager, Head Office of omnichannel retailer)

A vital part of ensuring successful online grocery retailing is the fulfilment of the 'perfect' customer order. Because the retailer supplies online customers from an 'in-store' fulfilment model, they incur additional costs to move products around (i.e. moving products which are out of stock from one store to the next to fulfil the 'perfect' order). During the interview, the online manager suggested that the movement of inventory between stores combined with the subsidy in terms of the delivery is resulting in an unsustainable online service model. The manager stated:

'... the cost implications of carrying inventory for online are staggeringly high $\ldots$ because of our availability challenges, we move thousands and thousands of products between stores on a daily, monthly, weekly basis. We move millions of rands worth of merchandise a year between stores on demand from customers.' (Personal interview, E-commerce operations manager, Head Office of omnichannel retailer)

From the above, it is evident that physical distribution is a challenge for omnichannel retailers because these retailers incur additional costs to offer the service. Furthermore, online grocery retailing in developing countries such as South Africa is still in its infant stage, which means fewer orders and unutilised capacity such as delivery trucks. The last mile of the supply chain also includes the return of products consumers are unsatisfied with, that is, reverse logistics. Reverse logistics will be discussed next as the final logistical challenge for omnichannel retailers in an e-supply chain.

\section{Reverse logistics}

Product returns are dreadful for online retailers as well as for consumers. From a consumer's point of view, groceries purchased online are only convenient if they are delivered to them at the right place, at the right time and in the proper condition. If this is not the case, the process of returning the product makes the online shopping experience inconvenient, especially in the case of groceries which could potentially be perishable (Xing et al. 2011). Brick-and-mortar retailers have the benefit of providing the customer with the option of returning or exchanging the product immediately at one of their stores (Bernon et al. 2016). However, the relevance of reverse logistics in an online grocery supply chain is questionable. Taking merchandise physically back and into the system is particularly challenging and collecting unacceptable merchandise from consumers is costly. In addition, lose fresh produce such as oranges do not have barcodes. Therefore, the lack of data on these returned items makes the management of the inventory system difficult. Similarly, no consumer wants to store rotten tomatoes for 2 days before the omnichannel grocery retailer can arrange for the collection of poor quality food items. As mentioned previously, the unique characteristics of grocery products and specifically how consumers will be able to return unsatisfactory perishable products increase the ambiguity of omnichannel grocery retailing, as seen by this quote from the focus group participants:

'Let us say you buy milk, and you get it, and it is sour, what now?' (Participant 4, Focus group 1)

Hence, efficient returns management is a key to online retailing (Giménez \& Lourenço 2008). Online order fulfilment and the options consumers have to return unsatisfactory products complicate the monitoring and tracking of inventory in real-time. Nevertheless, the Internet has made it possible for retailers to collect valuable information on why consumers return products (Bernon et al. 2016). This information can then be utilised to improve the service offered to the consumer (Kämäräinen 2001). Reverse logistics in an online food supply chain is even more complicated, as it is just not worth the omnichannel retailers' while to incur additional costs to collect foods from the consumers' homes which could not be reused. During the interview, the online manager indicated that they refund consumers right off the bat requesting returns. He also indicated that they do not currently have the capacity to track returns:

'Right now we do not track returns for online in any way. We are going to have to in the future.' (Personal interview, E-commerce operations manager, Head Office of omnichannel retailer)

Although the perishable nature of some grocery items makes reverse logistics or returns almost impossible as indicated at the beginning of this section, returns are sometimes unavoidable, even more so with online retailing considering that consumers do not select the product themselves. The challenge is to find ways to minimise returns of online grocery merchandise. However, until omnichannels do not implement an efficient returns management and tracking system, it will be difficult to determine why consumers are returning their online grocery items.

\section{Conclusion}

The purpose of the article was to gain an understanding of the nature of last-mile logistical challenges hindering the efficiency of an omnichannel grocery retailer in South Africa. The study found four significant last-mile logistical challenges. These logistical challenges pose challenges for omnichannels everywhere. However, the specific circumstances in a developing country such as South Africa and the particular delivery model of the omnichannel retailer pose unique challenges. Figure 2 serves as a visual representation of the findings of the study, indicating the issues identified during phase 1 of data analysis as well as the codes, categories and themes discussed as part of the findings section of this article.

The following conclusions and managerial recommendations can be made in relation to each of the four last-mile logistical challenges.

\section{Reliable fulfilment of online orders}

Online customers expect perfect order fulfilment, which is very difficult to attain. Although the omnichannel retailing 


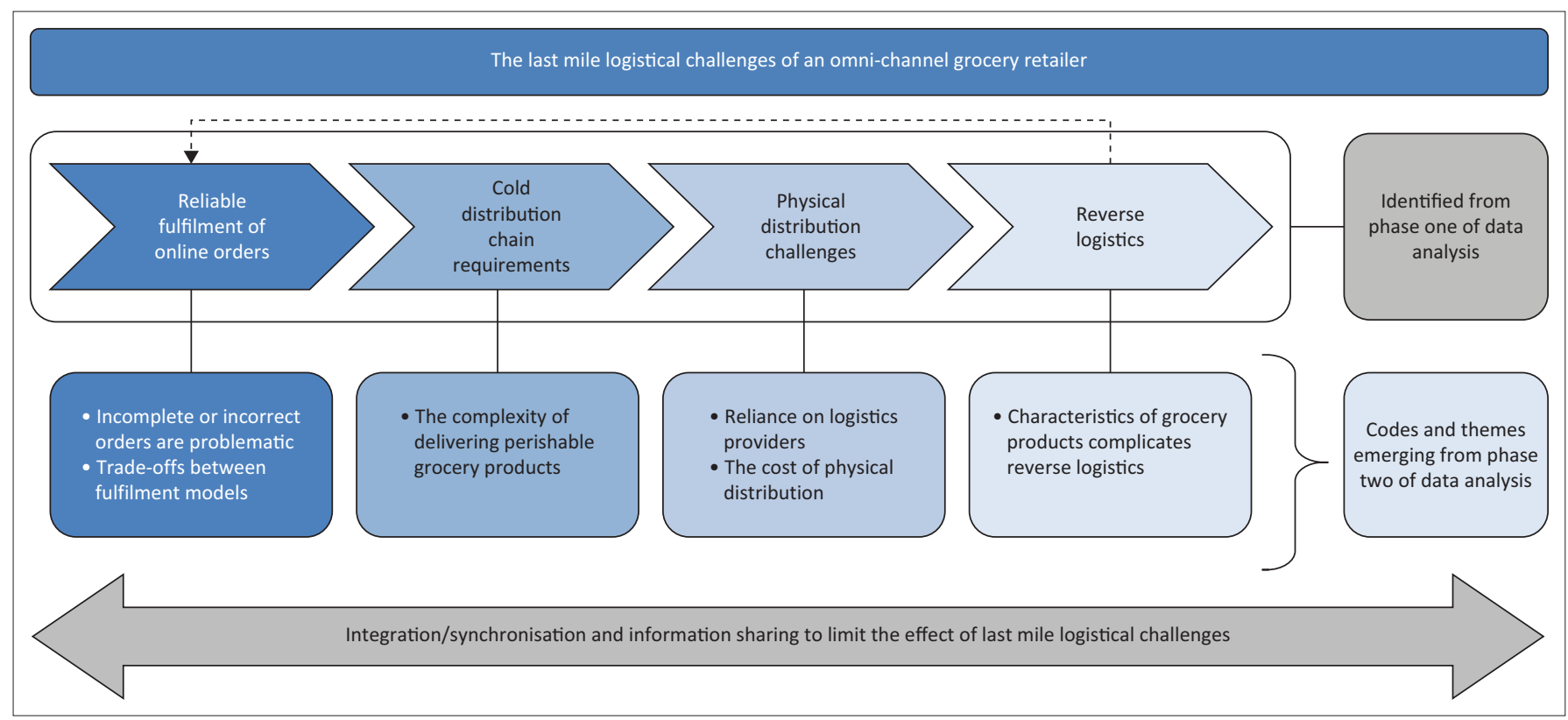

FIGURE 2: The last-mile logistical challenges of an omnichannel grocery retailer.

firm that participated in the study has a low percentage of non-compliance, they realise that it is not good enough as a result or 'spoilt consumers' who have a variety of grocery stores in their area. The omnichannel retailing firm has brick-and-mortar retail shops all over the country and uses these shops to fulfil online customers' orders. This poses a specific challenge as real-time inventory information needs to be updated continuously. To overcome this challenge, omnichannel grocery retailers need to improve information sharing along the grocery supply chain or have an integrated information system.

\section{Cold distribution chain requirements}

The perishability of many merchandise items makes special vehicles and delivery time important aspects. South Africa is characterised by a wide geographic spread of the population which poses specific problems in relation to the delivery of grocery items. This limits the market span to large metro areas in the country. As the online grocery ordering and delivery service become more popular, retailers should minimise this challenge. However, in order to address this challenge, omnichannel retailers should consider alternative logistics or delivery arrangements, such as fewer delivery options for low-density areas.

\section{Physical distribution challenges}

Because logistics is not the core business of grocery retailers, last-mile distribution is often outsourced to third parties. This is also the case with the omnichannel retailing firm that participated in the study. Outsourcing poses many risks for organisations such as reputational risks. Although the participating omnichannel retailing firm admits their vulnerability to outsourcing the distribution, they indicated that they have a strong logistics partner who proved to be reliable and contributed to the efficiency of the business.
Because of the geographically dispersed market and ease of a variety of brick-and-mortar grocers in suburban areas in South Africa, orders are few and spread between large delivery spaces. To address this, the participating omnichannel retailing firm indicated that they deliver orders with vehicles that are already on-route for other business purposes. Additionally, the cost of delivery is very high. Consequently, the omnichannel retailer indicated that they heavily subsidise the delivery cost. They realise that a high delivery cost can be a barrier to customers to shop online. Because of the model they use for fulfilling the online orders, many merchandise items are moved around shops, which is quite costly. To mitigate this challenge, omnichannel grocery retailers should effectively utilise data insights to adapt their physical distribution models to be more cost-effective, for example, use delivery vehicles for other purposes during low utilisation times.

\section{Reverse logistics in online grocery retailing}

Reverse logistics is a challenge for most omnichannel grocery retailers. The participating omnichannel retailing firm admitted that not enough attention is given to reverse logistics and that they have no system of tracking the reverse flow of groceries. The introduction of such a system would help the retailer to determine why consumers are returning grocery products. This will allow omnichannel retailers to address the root of the problem.

The conclusion can be made that each of these last-mile logistical challenges have sub-challenges, which inhibit the efficiency of these omnichannel retailers to a large extent. Considering the findings of the interview, it could be argued that the majority of these challenges could be alleviated through improved and efficient information sharing and synchronisation within the last mile of the supply chain. The managerial implications of this article suggest that to improve 
the efficiency of an omnichannel strategy, emphasis should be placed on implementing a fully integrated information sharing system. This could decrease the influence of the challenges discussed in this article. This article contributes by qualitatively exploring the major last-mile logistical challenges faced by omnichannel retailing.

\section{Limitations and future research opportunities}

As with most research, the researchers acknowledge the following limitations of this study: firstly, considering the topic under investigating, only a qualitative research design would allow the researchers to achieve the aim of the study. However, normally the findings of qualitative research are not generalisable. In addition, because there are only two omnichannel grocery retailers in South Africa, the researchers were dependent on the participation of these retailers. Consequently, one of the major limitations of the study is that the second omnichannel retailer declined an interview with the researchers. A comparison between the two omnichannel grocery retailing firm's last-mile logistical challenges would have contributed to the final results and the generalisability of the study for South African circumstances.

In this article, several last-mile logistical challenges were identified; one of the main managerial recommendations and conclusions of this article is that most of these challenges stem from insufficient information management along the supply chain. Future research should focus on information management for omnichannel supply chains by considering the types of information needed to alleviate the last-mile logistical challenges identified in this article, as well as the type of information technology systems necessary to improve the last-mile efficiency of omnichannel supply chains.

\section{Acknowledgements Competing interests}

The authors declare that they have no financial or personal relationships that may have inappropriately influenced them in writing this article.

\section{Authors' contributions}

Ms. A.N.W was the primary researcher under the supervision of J.A.B-W. The article was conceptualised, written and prepared for publication by both authors.

\section{References}

Aiello, G., La Scalia, G. \& Micale, R., 2011, 'Simulation analysis of cold chain performance based on time-temperature data', Production Planning and Control: The Management of Operations 23(6), 468-476. https://doi.org/10.1080/095372 87.2011.564219

Ailawadi, K. \& Farris, P., 2017, 'Managing multi- and omni-channel distribution: Metrics and research directions', Journal of Retailing 93(1), 120-135. https://doi. org/10.1016/j.jretail.2016.12.003

Al-Nawayseh, M.K., Alnabham, M.M. Al-debei, M.M. \& Balachandra, W., 2013, 'An adaptive decision support system for last mile logistics and e-commerce: A study on online grocery shopping', International Journal of Decision Support Systems Technology 5(1), 40-65. https://doi.org/10.4018/jdsst.2013010103
Bernon, M. Cullen, J. \& Gorst, J., 2016, 'Online retail returns management', International Journal of Physical Distribution and Logistics Management 46(6/7) 584-605. https://doi.org/10.1108/IJPDLM-01-2015-0010

Braun, V. \& Clarke, V., 2013, Successful qualitative research: A practical guide for beginners, Sage, London.

BusinessTech, 2018, SA unemployment rate unchanged at $26.7 \%$, viewed from https:// businesstech.co.za/news/business/244619/sa-unemployment-rate-unchangedat-26-7l

Carcary, M., 2009, 'The research audit trial - Enhancing trustworthiness in qualitative inquiry', The Electronic Journal of Business Research Methods 7(1), 11-24.

Cascone, J., Dayton, B., Ladd, B., Hillman, A. \& Alderman, M., 2015, Achieving assurance of supply in an omni-channel world, Deloitte, viewed 13 March 2018, from https:// www2.deloitte.com/content/dam/Deloitte/global/Documents/Consumer-Business/ gx-cb-supply-chain-omnichannel-020315.pdf

Chopra, S., 2016, 'How omni-channel can be the future of retailing', Decision 43(2), 135-144. https://doi.org/10.1007/s40622-015-0118-9

Chopra, S. \& Meindl, P., 2016, Supply chain management: Strategy, planning, and operation, 6th edn., Pearson, Essex.

Consumer Goods Forum (CGF), 2015, Re-engineering the supply chain for omnichannel of tomorrow. Global consumer goods and retail omnichannel supply chain survey, viewed 05 October 2016, from https://www.ey.com/Publication/vwLUAssets/EYre-engineering-the-supply-chain-for-the-omni-channel-of-tomorrow/\%24FILE/EYre-engineering-the-supply-chain-for-the-omni-channel-of-tomorrow/\%
re-engineering-the-supply-chain-for-the-omni-channel-of-tomorrow.pdf

Cooper, D.R. \& Schindler, S.P., 2014, Business research methods, 12th edn., McGraw Hill, Boston, MA.

Coyle, J.J., Langley, C.J., Novack, R.A. \& Gibson, B.J., 2017, Supply chain management: A logistics perspective, 10th edn., Cengage Learning, Boston, MA.

Creswell, J.W., 2009, Research design: Qualitative, quantitative and mixed methods approaches, Sage, Thousand Oaks, CA.

Cummins, S., Peltier, J.W. \& Dixon, A., 2016, 'Omnichannel research framework in the context of personal selling and sales management: A review and research extensions', Journal of Research in Interactive Marketing 10(1), 2-16. https://doi. org/10.1108/JRIM-12-2015-0094

Eriksson, P. \& Kovalainen, A., 2008, Qualitative methods in business research, Sage, Thousand Oaks, CA.

Fairchild, A.M., 2016, 'What is the role of Third Party Logistics (3PL) partners in an omni-channel strategy?', International Journal of Operations Research and Information Systems 7(1), 22-32. https://doi.org/10.4018/IJORIS.2016010102

Gallino, S. \&. Moreno, A., 2014, 'Integration of online and offline channels in retail: The impact of sharing reliable inventory availability information', Management Science 60(6), 1434-1451. https://doi.org/10.1287/mnsc.2014.1951

Gevaers, R., Van de Voorde, E. \& Vanelslander, T., 2014, 'Cost modelling and simulation of last-mile characteristics in an innovative $\mathrm{B} 2 \mathrm{C}$ supply chain environment with implications on urban areas and cities', Procedia-Social and behavioural Sciences 125, 398-411. https://doi.org/10.1016/j.sbspro.2014.01.1483

Giménez, C. \& Lourenço, H.R., 2008, 'e-SCM: Internet's impact on supply chain processes', The International Journal of Logistics Management 19(3), 309-343. https://doi.org/10.1108/09574090810919189

Hsu, M.K., Huang, Y. \& Swanson, S., 2010, 'Grocery store image, travel distance, satisfaction and behavioural intentions', International Journal of Retail and Distribution Management 38(2), 115-132. https://doi.org/10.1108/0959055 1011020129

Hübner, A., Kuhn, H. \& Wollenburg, J., 2016, 'Last mile fulfilment and distribution in omnichannel grocery retailing. A strategic framework', International Journal of Retail and Distribution Management 44(3), 228-247. https://doi.org/10.1108/ IJRDM-11-2014-0154

Ishfaq, R., Defee, C., Gibson, B.J. \& Raja, U., 2016, 'Realignment of the physical distribution process in omni-channel fulfilment', International Journal of Physical Distribution and Logistics Management 46(6/7), 543-561. https://doi.org/10.1108/ IJPDLM-02-2015-0032

Johnson, P.F, Leenders, M.R. \& Flynn, A.E., 2011, Purchasing and supply management, 14th edn., McGraw-Hill, New York.

Kämäräinen, V., 2001, 'The reception box impact on the home delivery efficiency in the e-grocery business', International Journal of Physical Distribution and Logistics Management 31(6), 414-426. https://doi.org/10.1108/096000301103 99414

Kumar, S., 2008, 'A study of the supermarket industry and its growing logistics capacities', International Journal of Retail and Distribution Management 5(1), 15-21. https://doi.org/10.1108/09590550810859150

Kuo, J. \& Chen, M., 2010, 'Developing an advanced multi-temperature joint distribution system for the food cold chain', Food Control 21, 559-566. https:// doi.org/10.1016/j.foodcont.2009.08.007

Lim, S.F.W.T., Jin, X. \& Srai, J.S., 2018, 'Consumer-driven e-commerce: A literature review, design framework, and research agenda on last-mile logistics models', International Journal of Physical Distribution \& Logistics Management 48(3), 308-332. https://doi.org/10.1108/IJPDLM-02-2017-0081

Mahar, S., Wright, D.P. \& Bretthauer, K.M., 2011, 'Dual channel supply chains: Challenges and opportunities in e-fulfilment', Production and Inventory Management Journa $47(2), 14-30$.

Mangiaracina, R., Marchet, G., Perotti, S. \& Tumino, A., 2015, 'A review of the environmental implications of B2C e-Commee: A logistical perspective', International Journal of Physical Distribution and Logistics Management 45(6), 565-591. https://doi.org/10.1108/IJPDLM-06-2014-0133 
Marchet, G., Melacini, M., Perotti, S., Rasini, M. \& Tappia, E., 2018, 'Business logistics models in omni-channel: A classification framework and empirical analysis', International Journal of Physical Distribution \& Logistics Management 48(4), 439-464. https://doi.org/10.1108/IJPDLM-09-2016-0273

Meyer, A., Niemann, W., Mackenzie, J. \& Lombaard, J., 2017, 'Drivers and barriers of reverse logistics practices: A study of large grocery retailers in South Africa' Journal of Transport and Supply Chain Management 11(0), a323. https://doi. org/10.4102/jtscm v11i0.323

Milkman, K.L., Rogers, T. \& Bazerman, M.H., 2010, 'I'll have the ice cream soon and the vegetables later: A study of online grocery purchases and order lead time', Marke Letters 21, 17-35. https://doi.org/10.1007/s11002-009-9087-0

Mirsch, T., Lehrer, C. \& Jung, R., 2016, 'Channel integration towards omnichanne management: A literature review', paper presented at the Pacific Asian Conference on Information Systems, PACIS, Chiayi, Taiwan, June 27-July 1.

Monczka, R.M, Handfield, R.B., Guinipero, L.C. \& Patterson, J.L., 2016, Purchasing and supply chain management, 6 th edn, Cengage, Boston, MA.

Mortimer, G., Fazal e Hasan, S., Andrews, L. \& Martin, J., 2016, 'Online grocery shopping: The impact of shopping frequency on perceived risk', The Internationa Review of Retail, Distribution and Consumer Research 26(2), 202-223. https://doi. org/10.1080/09593969.2015.1130737

Neergaard, M.A., Olesen, F., Andersen, R.S. \& Sondergaard, J., 2009, 'Qualitative description - The poor cousin of health research?', Bio Medical Central Medical Research Methodology 9(52), 1-5. https://doi.org/10.1186/1471-2288-9-5

O'Cass, A. \& Carlson, J., 2012, 'An e-retailing assessment of perceived website-service innovativeness: Implications for website quality evaluations, trust, loyalty and word of mouth', Australasian Marketing Journal 20, 28-36. https://doi.org/ 10.1016/j.ausmj.2011.10.012

Piotrowicz, W. \& Cuthbertson, R., 2014, 'Information technology in retail: Towards omnichannel retailing', International Journal of Electronic Commerce 18(4), 5-15. omnichannel retailing', International Journal of
https://doi.org/10.2753/JEC1086-4415180400

Plano Clark, V.L. \& Creswell J.W., 2015, Understanding research: A consumer's guide, Pearson, Upper Saddle River, NJ.

Punakivi, M. \& Saranen, J., 2001, 'Identifying the success factors in e-grocery home delivery', International Journal of Retail and Distribution Management 29(4), 156-163. https://doi.org/10.1108/09590550110387953

Rafiq, M. \& Fulford, H., 2005, 'Loyalty transfer from offline to online stores in the UK grocery industry', International Journal of Retail and Distribution Managemen 33, 444-460. https://doi.org/10.1108/09590550510600861

Reinartz, W., Dallaert, B., Krafft, M., Kumar, V. \& Varadarajan, R., 2011, 'Retailing innovations in a globalizing retail market', Journal of Retailing 87, 53-66. https:// doi.org/10.1016/j.jretai.2011.04.009

Rong, A., Akkerman, R. \& Grunow, M., 2011, 'An optimization approach for managing fresh food quality throughout the supply chain', International Journal Production Economics 131, 421-429. https://doi.org/10.1016/j.ijpe.2009.11.026
Saldaña, J., 2011, Fundamentals of qualitative research, Oxford University Press, New York.

Sezen, B., 2008, 'Relative effects of design, integration and information sharing on supply chain performance', Supply Chain Management: An International Journal 13(3), 233-240. https://doi.org/10.1108/13598540810871271

Shenton, A.K., 2004, 'Strategies for ensuring trustworthiness in qualitative research projects', Education for Information 22, 36-57. https://doi.org/10.3233/EFI-200422201

Smith, J. \& Firth, J., 2011, 'Qualitative data analysis: The framework approach', The International Journal of Research Methodology in Nursing and Health Care 18(2), 52-62. https://doi.org/10.7748/nr2011.01.18.2.52.c8284

Statistics South Africa, 2016, 'Quarterly labour force survey', Statistics South Africa May 9, viewed 16 July 2018, from https://www.statssa.gov.za/publications/ P0211/P02111stQuarter2016.pdf

Turner, D.W., 2010, 'Qualitative interview design: A practical guide for novice investigators', The Qualitative Report 15(3), 754.

Vaismoradi, M., Turenen, H. \&. Bondas, T., 2013, 'Content analysis and thematic analysis: Implications for conducting a qualitative descriptive study', Nursing and Health Sciences 15, 398-405. https://doi.org/10.1111/nhs.12048

Van Zyl, G., 2015., FNB rated as SA's 'top internet banking provider', viewed 10 July 2016, from http://www.fin24.com/Tech/News/FNB-rated-SAs-top-internet-bankingprovider-20150507

Verhoef, P., Kannan, P. \& Inman, J., 2015, 'From multi-channel retailing to omnichannel retailing', Journal of Retailing 91(2), 174-181. https://doi.org/10.1016/j. jretai.2015.02.005

Weber, A.N. \&. Badenhorst-Weiss, J.A., 2016, 'Time-based competition as a competitive strategy for online grocery retailers', Journal of Contemporary Management 13, 433-460.

Wisner, J.D., Tan, K.C. \& Leong, G.K., 2016, Supply chain management: A balanced approach, 4th edn., student edition, South-Western Cengage Learning, Manson, $\mathrm{OH}$

World Economic Forum (WEF), 2016, Global competitiveness report 2016-2017, World Economic Forum, Geneva.

Xing, Y., Grant, G.B., McKinnon, A.C. \& Fernie, J., 2011, 'The interface between retailers and logistics service providers in the online market', European Journal of Marketing 45(3), 334-357. https://doi.org/10.1108/03090561111107221

Yrjölä, H., 2001, 'Physical distribution considerations for electronic grocery shopping. International', Journal of Physical Distribution and Logistics Management 31(10), 746-761. https://doi.org/10.1108/09600030110411419

Zarella, E., Chamberlain, R. \& Liddell, P., 2016, The future of retail supply chains, KPMG nternational. 